\title{
Impact of smartphone usage on cervical proprioception and balance in healthy adults.
}

\author{
Adel Alshahrani ${ }^{1}$, Sobhy M Aly ${ }^{1,2}$, Mohamed Samy Abdrabo ${ }^{1,3}$, Faisal Y. Asiri4* \\ ${ }^{1}$ Department of Physical Therapy, College of Applied Medical Sciences, Najran University, Najran, KSA \\ ${ }^{2}$ Department of Biomechanics, Faculty of Physical Therapy, Cairo University, Cairo, Egypt \\ ${ }^{3}$ Department of Basic Sciences, Faculty of Physical Therapy, Cairo University, Cairo, Egypt \\ ${ }^{4}$ Department of Physical Therapy, College of Applied Medical Sciences, King Khalid University, Abha, KSA
}

\begin{abstract}
Purpose: Individuals are utilizing smartphones for different tasks on a daily basis. Prolonged smartphone usage might lead to deficient postures such as forward head posture and rounded shoulders. The purpose of this study was to look at the impact of the heavy use of smartphones versus light use on Joint Position Error (JPE), Craniovertebral Angle (CVA), and balance measures.

Method: Thirty healthy participants were recruited in this study, and they were divided into two groups: light use (phone use $<4 \mathrm{~h} / \mathrm{d}$ ) and heavy use (phone use $>4 \mathrm{~h} / \mathrm{d}$ ). Subjects were assessed for cervical repositioning errors using the JPE test. Forward head posture was measured by CVA. Dynamic balance was assessed using the Biodex stability system.

Results: There was a significant increase in JPE of both right and left rotation in the heavy-use group compared with that of light-use group. Also, there was a significant increase in balance indices in the heavy-use group. However, there was no significant difference in CVA between groups.

Conclusion: Our study showed that prolonged duration of smartphone use could negatively affect cervical proprioception and dynamic balance ability. Further considerations are required to outline the negative impacts of heavy usage of smartphones and to implement preventive measures.
\end{abstract}

Keywords: Cervical spine, Joint position error, Craniovertebral angle, Balance, Smartphone usage.

Accepted on May 4, 2018

\section{Introduction}

Nowadays, people are becoming more dependent on smartphones than ever. During the day, individuals are utilizing smartphones for different tasks on a daily basis. These tasks include checking social media connections, watching videos, reading books, doing some form of work, browsing the internet and other functions [1] that may predispose to musculoskeletal deficits $[2,3]$. People engaging with the visual display terminal of a smartphone gradually develop forward head posture as a compensatory posture and at work, this has been put down to either poor workhabits or ergonomically poor workstation arrangements [4].

Several studies have investigated the impact of using smartphones on pain created in different parts of the body, and there is a correlation between the amount of time spent using a smartphone and the severity of the symptoms $[3,5,6]$. Not only that, other studies have shown that prolonged cell phones usage might lead to deficient postures, such as forward head posture and rounded shoulders [7,8]. Hansraj et al. found in their research that the angled weight of the head increase as the degree of the neck flexion increases, respectively, and with 60 degrees of head flexion the weight of the head reaches around $28 \mathrm{~kg}$ [9]. Moreover, the impact of prolonged smartphones usage may lead to respiratory dysfunction due the faulty posture of the neck [8].

There is some evidence that neck joints are becoming under more stress due to sustained hunching over smartphones [10]. There is an increasing incidence of neck pain in different age groups [3]. Usually, neck pain increases as age increases, but nowadays younger patients are reporting neck pain more than ever [6]. Sustained pressure on the neck joints [10] is causing disturbed signals to the brain that might cause balance problems and disturbed neck proprioception [5,7,11]. Proper balance and controlling head and eye movements is dependent on afferent input from different systems at the same time. These systems' information needs to be integrated depending on the task and environment, and they include vision, vestibular, and proprioception systems [12]. Cervical proprioception contributes to correct head in space and trunk orientation [13], as well as to correct body orientation and balance control [14]. 
Previous studies suggested that the complex reflex and central interaction between cervical proprioception, vestibular and visual information are necessary for optimal orientation and postural control [15-20]. This interaction becomes even more evident when vestibular or visual information fails $[21,22]$. Child et al. showed that people with neck pain are more likely to have poor balance and poor coordination of head movement [23]. The sensorimotor dysfunction component can cause increased postural sway when measured in a standing position [24]. Moreover, it causes difficulty in positioning the head to a predetermined position [13]. These studies demonstrate how important the afferent information from the neck joints for postural control is. Posture seems to have a great impact on the sensorimotor function of the cervical spine. With people spending so much time using smartphones, they are more likely to have their neck in an incorrect position for a long period, which might affect the proprioception input of the neck. Based on the strong interrelation between the cervical spine and posture [9,25], the purpose of this study was to look at the impact of the heavy use of smartphones versus light use on Joint Position Error (JPE), the Craniovertebral Angle (CVA), and balance measures.

\section{Material and Methods}

\section{Subjects}

This is a cross-sectional study that was conducted on 30 healthy participants aged from 18 to 27 years old recruited from the faculty of Applied Medical Sciences, Najran University, Saudi Arabia. The researchers divided the subjects into two groups; light smartphone use and heavy smartphone use; according to the report on the participants. The light-use group was comprised of subjects who used a smartphone for less than four hours per day, and the heavy-use group was comprised of subjects who used a smartphone for four hours or more per day. Four hours was selected as a cut off as Jung et al. reported that subjects who use smartphone more than 4 hours per day had lower CVA and partly impaired respiratory function compared with subjects who use smartphoneless than $4 \mathrm{~h}$ per day [8].

Exclusion criteria included: neck pain, any cervical trauma or fracture, progressive neurological disease, orthopedic condition, any vestibular pathology or dizziness. All subjects were aware of the purpose of the study before signing the consent form. This study was carried in accordance with the Declaration of Helsinki and approved by the ethics committee of Najran University.

\section{Instrumentation}

In this study, a laser beam and colored target were used to measure the JPE. The laser method has been applied to measure cervical JPE [26,27]. This method has demonstrated good test-retest reliability and has been shown to have excellent correlation with an ultrasound technique for measurement of JPE [28]. The laser pointer was attached to a lightweight headband on top of the head. The distance between the starting point projected by the laser from the forehead to the center of the target was standardized at $90 \mathrm{~cm}$, using a measuring tape.

The measured variable is the difference between the start and returning position of the laser beam on the target and was recorded in degrees using the formula, angle $=\tan ^{-1}$ (error distance $/ 90 \mathrm{~cm})[28]$.

\section{Biodex stability system}

Dynamic balance was assessed using the Biodex stability system (Biodex, Inc., Shirley, NY). The Biodex Stability System (BSS) is a multiaxial device that uses a circular platform. It can tilt up to $20^{\circ}$ in a $360^{\circ}$ arc of motion, and it is interfaced with specialized software (Biodex, Version 3.1, Biodex Medical Systems). BBS software calculates three separate measurements: Overall Stability Index (OSI), Anterior-Posterior Stability Index (APSI) and medial-lateral stability index (MLSI) with higher scores indicating worse postural control. The intratester reliability of this procedure has been previously reported as 0.43 for medial-lateral stability index, 0.80 for the anterior-posterior stability index, and 0.82 for the overall stability index [29].

\section{Procedure}

CVA evaluation: Craniovertebral Angle (CVA) was measured by asking the patient to sit in a comfortable position that they usually sit in. A photograph was taken using a digital camera (Nikon D7100) from the lateral side. The camera was placed perpendicular to the horizontal plane. The angle was measured on the connection point of two lines. One line was from the $7^{\text {th }}$ vertebra to the tragus, and the other line was the horizontal line passing through the $7^{\text {th }}$ cervical spine $[8,30]$. Asking the subject to flex and extend their neck identified the $7^{\text {th }}$ cervical vertebra as the most prominent cervical spine. Two researchers agreed on the landmark of the spinous process of $7^{\text {th }}$ vertebra. Adobe Photoshop CS6 was used to measure the CVA.

JPE evaluation: Cervical repositioning errors were assessed [31] while the subjects were in a sitting position. The participants were in a chair with arm and back support. Their feet were placed supported on the floor with knee, and hip at $90^{\circ}$ and subjects were asked to maintain this position throughout the full test. The laser pointer was fixed on the top of the subject head with a strap and tape to make sure it did not move. The subjects performed three trials to become familiar with the test and then they were asked to perform three attempts of rotation through the available range of motion without stress to one side then return back to the starting position. The mean score of the three attempts on each side was calculated and recorded as JPE. Rotation of both sides was evaluated. The eyes of the subjects were covered to make sure that the participants could not observe the laser pointer and then try to adjust their head position [28].

Balance evaluation: Participants were tested while wearing comfortable footwear, with their eyes open, and they were allowed to visualize the real-time feedback provided by the 
BSS computer interface. Participants were instructed to maintain their arms by their sides and look straight ahead to the display screen. The researchers instructed the participants to keep the cursor in the smallest concentric rings (balance zones) of the BSS. The centering process consisted of unlocking the platform to allow motion. The participants were instructed to adjust the position of their feet until they found a position where they were able to maintain platform stability. The process was guided by visual feedback on the screen as the cursor moved until it was easy to keep the cursor centered on the screen grid while standing in a comfortable upright position. Once the participant was centered, they were asked to maintain their feet position until the platform was stabilized. Heel coordinates and feet angles from the platform were recorded. All participants were trained one minute prior to the assessment for adaptation to the machine, followed by three practice trials, each trial consisting of a $30 \mathrm{~s}$ evaluation, starting on level eight (most stable) and gradually decreasing to level 1 (least stable). The mean score was calculated from the three test evaluations. A $60 \mathrm{~s}$ rest was given between trials.

\section{Outcome measures}

Cervical repositioning errors were measured with the JPE test. JPE greater than $4.5^{\circ}$ is thought to suggest impairment in repositioning accuracy of the head and neck [26,28]. Forward head posture was measured by CVA. The balance was measured by OSI, APSI and MLSI.

\section{Data analysis}

Subject characteristics were compared between both groups using the t-test. Multivariate Analysis of Variance (MANOVA) was carried out to compare the mean values of CVA, JPE and stability indices between light-use and heavy-use groups. One sample $t$ test was performed to compare the JPE to normal value. The level of significance for all statistical tests was set at $\mathrm{p}<0.05$. All statistical analyses were conducted through the Statistical Package for Social Studies (SPSS) version 19 for Windows (IBM SPSS, Chicago, IL, USA).

\section{Results}

\section{Subject characteristics}

Table 1, showed the mean \pm SD age, weight, height and BMI of the smartphone light- and heavy-use groups. There was no significant difference between both groups in the mean age, weight, height, and BMI ( $\mathrm{p}>0.05)$.

\section{Comparison of CVA, JPE and stability indices between the smartphone light- and heavy-use groups}

There was a significant group effect (Wilks' Lambda $=0.55, \mathrm{~F}$ $(6,23)=3.03, p=0.02)$. Table 2 shows descriptive statistics of dependent variables as well as the significant level of comparison between the two groups.
There was a significant increase in JPE of both right and left rotation in the heavy-use group compared with that of light-use group $(\mathrm{p}<0.01)$. Also, there was a significant increase in OSI, APSI, and MLSI in the heavy-use group compared with that of the light-use group $(p<0.05)$. However, there was no significant difference in CVA between the two groups $(\mathrm{p}=0.59)$.

\section{Comparison of JPE of light- and heavy-users to normal value}

There was a significant decrease in the right and left JPE of the light smartphone users compared with the normal value of 4.5 $(p>0.01)$, while there was a significant increase in the right and left JPE of the heavy smartphone users compared with the normal value of $4.5(\mathrm{p}>0.05)$.

Table 1. Comparison of the mean age, weight, height and BMI of smartphone light-and heavy-use groups.

\begin{tabular}{llllll}
\hline & Light use & Heavy use & MD & t- value & p-value \\
\cline { 2 - 4 } & $\overline{\mathrm{x}} \pm \mathrm{SD}$ & $\overline{\mathrm{x}} \pm \mathrm{SD}$ & & & \\
\hline Age $(\mathrm{y})$ & $23.1 \pm 1$ & $23.5 \pm 2.7$ & -0.4 & -0.63 & 0.52 \\
\hline Weight $(\mathrm{kg})$ & $63.3 \pm 8.1$ & $65.8 \pm 5.5$ & -2.5 & -1 & 0.32 \\
\hline Height $(\mathrm{cm})$ & $170.2 \pm 6.6$ & $169.9 \pm 7.8$ & 0.3 & 0.1 & 0.92 \\
\hline BMl $\left(\mathrm{kg} / \mathrm{m}^{2}\right)$ & $21.9 \pm 3.2$ & $22.9 \pm 2.6$ & -1 & -0.93 & 0.36 \\
\hline $\begin{array}{l}\overline{\mathrm{x}} \text { : Mean; SD: } \\
\text { significance. }\end{array}$ & & & & & \\
\hline
\end{tabular}

Table 2. Comparison of the mean value of CVA, JPE and stability indices between light-and heavy-use groups.

\begin{tabular}{|c|c|c|c|c|}
\hline & \multirow{2}{*}{$\begin{array}{l}\text { Light use } \\
\bar{x} \pm \text { SD }\end{array}$} & \multirow{2}{*}{$\begin{array}{l}\text { Heavy use } \\
\bar{x} \pm \text { SD }\end{array}$} & \multirow[t]{2}{*}{ MD } & \multirow[t]{2}{*}{ p-value } \\
\hline & & & & \\
\hline CVA (degrees) & $43.86 \pm 7.54$ & $42.4 \pm 7.34$ & -1.46 & 0.59 \\
\hline JPE on right side & $3.7 \pm 1$ & $5.4 \pm 1.6$ & -1.62 & $0.003^{*}$ \\
\hline JPE on left side & $3.6 \pm 0.9$ & $5.6 \pm 1.5$ & -1.92 & $0.001^{*}$ \\
\hline \multicolumn{5}{|c|}{ Balance assessment } \\
\hline OSI & $1.03 \pm 0.2$ & $1.55 \pm 0.82$ & -0.52 & $0.02^{*}$ \\
\hline APSI & $0.72 \pm 0.15$ & $1.08 \pm 0.62$ & -0.36 & $0.03^{*}$ \\
\hline MLSI & $0.55 \pm 0.17$ & $0.86 \pm 0.49$ & -0.31 & $0.03^{*}$ \\
\hline $\begin{array}{l}\bar{x}: \text { Mean; SD: St } \\
\text { significance. *Signi }\end{array}$ & Deviation; & \multicolumn{3}{|c|}{ Mean Difference; p-value, level o } \\
\hline
\end{tabular}

\section{Discussion}

This study looked at CVA, JPE, and balance measurements on healthy individuals who used smartphones for a long period of time $(4 \mathrm{~h}+)$ during any daytime. The results of our study showed no significant difference on CVA when comparison was made between smartphone heavy- and light-use individuals. However, we found a significant increase of JPE for right and left rotation and balance measures that included 
OSI, APSI, and MLSI in heavy-use individuals compared with that of light-use individuals.

The values of CVA $\left(42-44^{\circ}\right)$ obtained in both groups in the current study reflect the development of forward head posture, as subjects with forward head posture have a smaller CVA angle compared with normal subjects. Smaller CVA angles mean greater protraction and forward head posture, while larger angles reflect good head and neck alignment in the sagittal plane [32]. Yip et al., reported a CVA less than $50^{\circ}$ in subjects with forward head posture with neck pain, and the mean value of the control group was $55.02^{\circ}$ [33]. Jung et al., [8] concluded that subjects who use smartphones for more than four hours per day had a lower CVA.

The non-significant difference in CVA between the two groups may be attributed to the fact that the postural changes that occur in response to smartphone use may be related to the use of the phone and adaptive posture to this use rather than to the duration of use. Also, it may be attributed to the fact that the majority of the sample were college students who were involved in many similar educational activities like reading, writing, and computer use. These factors might be predisposed to forward-head posture as a postural adaptation to a visual display terminal. Forward head posture has been shown to be a common postural displacement, with an estimate of $66 \%$ of the patient population [34]. This finding is inconsistent with the results of Kim et al. [11] who reported a significant increase in flexion angles of the cervical spine in a group of prolonged-use smartphone users compared with a group of shorter-use smartphone users. The cause of this inconsistency may be explained as Kim et al. measured the angle following smartphone tasks of between three and $300 \mathrm{~s}$, while in our study we measured the adaptive posture assumed by the subjects.

Increased JPE in smartphone heavy users compared with light users may be attributed to the affection of neck proprioception from prolonged use of the smartphone. Prolonged forward neck posture may injure the structure of the cervical spine, as well as the ligament $[35,36]$. Poor performance in the JPE test reflects abnormal neck afferent input [37]. The joint position sense is crucial for head-on-trunk orientation [21]. Lee and Seo [38] investigated the impact of addiction to smartphone use on cervical repositioning error. They found that the severe addiction group showed the largest repositioning error. Also, Kim et al. [11] reported that prolonged use of a smartphone is associated with an increase in the reposition error.

The significant affection of balance score in smartphone heavy users may also be attributed to a disturbed cervical afferent function. Sustained muscle tension changes the sensitivity of neck proprioception which affects dynamic balance ability [27]. Cervical JPE is correlated significantly with balance tests [39]. The relationship between somatosensory information and balance is well established in the literature [40-44].

Our results regarding the decrease in balance ability agreed with Hyounk [45] and Cho et al. [46] who reported that using a smartphone while completing tasks reduced cognitive ability and decreased dynamic balance. Also, Laatar et al. [25] found that operating a smartphone increased the center of pressure displacement and impaired the standing postural balance of elderly and young adults.

We have some limitations in our study. We acknowledge that the number of subjects were relatively small $(n=34)$. Furthermore, the subjects' age group was 18-27 y old, so we do not know about younger or older age groups. Moreover, the measurements for our study were taken over a very short period of time and only once, which might allow subjects to adopt a posture that the participants might not have been able to tolerate for a longer period of time.

\section{Conclusion}

The result of this study has shown that a prolonged duration of using a smartphone could negatively affect cervical proprioception and dynamic balance ability. The negative impact of smartphone use should be outlined, and preventive measures should be considered.

\section{References}

1. Rainie L. Internet, broadband, and cell phone statistics. Pew Intern Am Life Proj 2010; 5.

2. Arslan A, Tutgun A. Examination of cell phone usage habits and purposes of education faculty students. J Human Sci 2013; 10: 20.

3. Berolo S, Wells RP, Amick III BC. Musculoskeletal symptoms among mobile hand-held device users and their relationship to device use: a preliminary study in a Canadian university population. Appl Ergonom 2011; 42: 371-378.

4. Gadotti IC, Biasotto-Gonzalez DA. Sensitivity of clinical assessments of sagittal head posture. J Eval Clin Pract 2010; 16: 141-144.

5. Al-Khlaiwi T, Meo SA. Association of mobile phone radiation with fatigue, headache, dizziness, tension and sleep disturbance in Saudi population. Saudi Med J 2004; 25: 732-736.

6. Kim GY, Ahn CS, Jeon HW, Lee CR. Effects of the use of smartphones on pain and muscle fatigue in the upper extremity. J Phys Ther Sci 2012; 24: 1255-1258.

7. AlZarea BK, Patil SR. Mobile phone head and neck pain syndrome: proposal of a new entity. Headache 2015; 251: 63.

8. Jung SI, Lee NK, Kang KW, Kim K, Do YL. The effect of smartphone usage time on posture and respiratory function. J Phys Ther Sci 2016; 28: 186-189.

9. Hansraj KK. Assessment of stresses in the cervical spine caused by posture and position of the head. Surg Technol Int 2014; 25: 277-279.

10. Park J, Kim J, Kim J, Kim K, Kim N, Choi I, Lee S, Yim J. The effects of heavy smartphone use on the cervical angle, pain threshold of neck muscles and depression. Adv Sci Technol Lett 2015; 91: 12-17. 
11. Kim YG, Kang MH, Kim JW, Jang JH, Oh JS. Influence of the duration of smartphone usage on flexion angles of the cervical and lumbar spine and on reposition error in the cervical spine. Phys Ther Korea 2013; 20: 10-17.

12. Horak FB. Postural orientation and equilibrium: what do we need to know about neural control of balance to prevent falls? Age Ageing 2006; 35: 7-11.

13. Armstrong B, McNair P, Taylor D. Head and neck position sense. Sports Med 2008; 38: 101-117.

14. Kavounoudias A, Gilhodes JC, Roll R, Roll JP. From balance regulation to body orientation: two goals for muscle proprioceptive information processing? Exp Brain Res 1999; 124: 80-88.

15. Karlberg M, Johansson R, Magnusson M, Fransson PA. Dizziness of suspected cervical origin distinguished by posturographic assessment of human postural dynamics. J Vestib Res 1996; 6: 37-47.

16. Mergner T, Huber W, Becker W. Vestibular-neck interaction and transformation of sensory coordinates. J Vestib Res 1997; 7: 347.

17. Persson L, Karlberg M, Magnusson M. Effects of different treatments on postural performance in patients with cervical root compression. J Vestib Res 1996; 6: 439-453.

18. Ruhe A, Fejer R, Walker B. Altered postural sway in patients suffering from non-specific neck pain and whiplash associated disorder-a systematic review of the literature. Chiropract Manual Ther 2011; 19: 13.

19. Treleaven J. Sensorimotor disturbances in neck disorders affecting postural stability, head and eye movement control. Manual Ther 2008; 13: 2-11.

20. Vuillerme N, Pinsault N. Experimental neck muscle pain impairs standing balance in humans. Exp Brain Res 2009; 192: 723-739.

21. Malmstrom EM, Karlberg M, Fransson PA, Lindbladh J, Magnusson M. Cervical proprioception is sufficient for head orientation after bilateral vestibular loss. Eur J Appl Physiol 2009; 107: 73-81.

22. Maurer C, Mergner T, Bolha B, Hlavacka F. Vestibular, visual, and somatosensory contributions to human control of upright stance. Neurosci Lett 2000; 281: 99-102.

23. Childs JD, Cleland JA, Elliott JM, Teyhen DS, Wainner RS, Whitman JM, Sopky BJ, Godges JJ, Flynn TW, Delitto A, Dyriw GM. Neck pain: clinical practice guidelines linked to the international classification of functioning, disability, and health from the orthopedic section of the American physical therapy association. J Orthop Sports Phys Ther 2008; 38: 1-34.

24. Field S, Treleaven J, Jull G. Standing balance: a comparison between idiopathic and whiplash-induced neck pain. Manual Ther 2008; 13: 183-191.

25. Laatar R, Kachouri H, Borji R, Rebai H, Sahli S. The effect of cell phone use on postural balance and mobility in older compared to young adults. Physiol Behav 2017; 173: 293-297.
26. Revel M, Andre-Deshays C, Minguet M. Cervicocephalic kinesthetic sensibility in patients with cervical pain. Arc Phys Med Rehab 1991; 72: 288-291.

27. Revel M, Minguet M, Gergoy P, Vaillant J, Manuel JL. Changes in cervicocephalic kinesthesia after a proprioceptive rehabilitation program in patients with neck pain: a randomized controlled study. Arc Phys Med Rehab 1994; 75: 895-899.

28. Roren A, Mayoux-Benhamou M-A, Fayad F, Poiraudeau S, Lantz D, Revel M. Comparison of visual and ultrasound based techniques to measure head repositioning in healthy and neck-pain subjects. Manual Ther 2009; 14: 270-277.

29. Schmitz R, Arnold B. Intertester and intratester reliability of a dynamic balance protocol using the Biodex stability system. J Sport Rehab 1998; 7: 95-101.

30. Kang JH, Park RY, Lee SJ, Kim JY, Yoon SR, Jung KI. The effect of the forward head posture on postural balance in long time computer based worker. Ann Rehab Med 2012; 36: 98-104.

31. de Vries J, Ischebeck BK, Voogt LP, van der Geest JN, Janssen M, Frens MA, Kleinrensink GJ. Joint position sense error in people with neck pain: a systematic review. Manual Ther 2015; 20: 736-744.

32. Shaheen AA, Basuodan RM. Quantitative assessment of head posture of young adults based on lateral view photographs. J Phys Ther Sci 2012; 24: 391-394.

33. Yip CH, Chiu TT, Poon AT. The relationship between head posture and severity and disability of patients with neck pain. Man Ther 2008; 13: 148-154.

34. Griegel-Morris P, Larson K, Mueller-Klaus K, Oatis CA. Incidence of common postural abnormalities in the cervical, shoulder, and thoracic regions and their association with pain in two age groups of healthy subjects. Phys Ther 1992; 72: 425-431.

35. Fernandez-de-Las-Penas C, Alonso-Blanco C, Cuadrado M, Pareja J. Forward head posture and neck mobility in chronic tension-type headache: a blinded, controlled study. Cephalalgia 2006; 26: 314-319.

36. Bonney RA, Corlett EN. Head posture and loading of the cervical spine. Appl Ergon 2002; 33: 415-417.

37. Taylor JL, McCloskey D. Illusions of head and visual target displacement induced by vibration of neck muscles. Brain 1991; 114: 755-759.

38. Lee J, Seo K. The comparison of cervical repositioning errors according to smartphone addiction grades. J Phys Ther Sci 2014; 26: 595-598.

39. Treleaven J, Jull G, LowChoy N. The relationship of cervical joint position error to balance and eye movement disturbances in persistent whiplash. Man Ther 2006; 11: 99-106.

40. Taimela S, Kankaanpaa M, Luoto S. The effect of lumbar fatigue on the ability to sense a change in lumbar position. A controlled study. Spine (Phila Pa 1976) 1999; 24: 1322-1327. 
41. Doumas M, Krampe RT. Adaptation and reintegration of proprioceptive information in young and older adults postural control. J Neurophysiol 2010; 104: 1969-1977.

42. Goble DJ, Mousigian MA, Brown SH. Compromised encoding of proprioceptively determined joint angles in older adults: the role of working memory and attentional load. Exp Brain Res 2012; 216: 35-40.

43. Goble DJ, Coxon JP, Van Impe A, Geurts M, Van Hecke W, Sunaert S, Wenderoth N, Swinnen SP. The neural basis of central proprioceptive processing in older versus younger adults: an important sensory role for right putamen. Hum Brain Mapp 2012; 33: 895-908.

44. Lord SR, Clark RD, Webster IW. Postural stability and associated physiological factors in a population of aged persons. J Gerontol 1991; 46: 69-76.

45. Hyong IH. The effects on dynamic balance of dualtasking using smartphone functions. J Phys Ther Sci 2015; 27: 527-529.
46. Cho SH, Choi MH, Goo BO. Effect of smart phone use on dynamic postural balance. J Phys Ther Sci 2014; 26: 1013-1015.

\section{*Correspondence to}

Faisal Y. Asiri

Department of Physical Therapy

College of Applied Medical Sciences

King Khalid University

Kingdom of Saudi Arabia 